\title{
BED STRESS INVESTIGATION UNDER BREAKING SOLITARY WAVE RUNUP
}

\author{
Mohammad Bagus Adityawan ${ }^{1 *}$, Hitoshi Tanaka² and Pengzhi Lin ${ }^{3}$
}

\begin{abstract}
The bed stress under a breaking solitary wave runup was investigated in this study using the Simultaneous Coupling Method (SCM). The SCM couples the shallow water equation (SWE) with the k- $\omega$ model. The depth averaged velocity from the SWE is applied as the upper boundary condition in the k- $\omega$ model for the bed stress assessment from the boundary layer. It was found that the boundary layer approach provides more accurate bed stress estimation than the empirical method, which leads to a more accurate prediction of the runup height and the wave profile. The accumulation of the bed stress during a solitary wave runup was evaluated. The bed stress in the direction of leaving the shoreline will have more impact in the overall process. However, during a short period of the runup process, the bed stress toward the shoreline may have significant effect as well.
\end{abstract}

Keywords: breaking wave; solitary wave; runup; bed stress; boundary layer

\section{INTRODUCTION}

The sediment transport process is one of the main parameters in the coastal morphology changes, especially during a tsunami event. The bottom boundary layer will play an important role in the bed stress behavior which is closely related to the sediment transport. The long wave approach is often used in tsunami studies which often involve numerical and laboratory works. Synolakis (1986) conducted a series of laboratory experiment measuring the runup of solitary waves along with the analytical solution for a solitary wave propagating over a constant depth and then running up a sloping beach, which is commonly referred as the canonical problem. The canonical problem is often used as a benchmark for validating numerical codes in the tsunami runup studies.

The shallow water equation (SWE) is commonly used for the tsunami runup simulation. Generally, the Manning method is applied to assess the bed stress term in the momentum equations. However, this method is inferior to direct approach from the boundary layer, especially in an unsteady wave motion. In detail, this assumption can not be used since the velocity and the bed stress do not always behave in a similar way. Tanaka and Thu (1994) have shown the importance of the friction and the phase differences between the velocity and the bed stress under waves. In general, the bed stress formulations may incorporate both the velocity and the acceleration related terms, or may include the phase lag (Kabiling and Sato 1993, Nielsen 2002). Nevertheless, the SWE model with the conventional Manning approach is still one of the most commonly used models since it is efficient with relatively good accuracy. The model has been used to simulate various cases of tsunami, including the 1993 Okushiri tsunami (Titov and Synolakis 1998), the 2004 Banda Aceh Tsunami (Kusuma et al. 2008). It was shown that the SWE provides a relatively accurate results and suitable for the practical application, although the model cannot explain the boundary layer in details.

Understanding the sediment transport processes under a wave motion requires a more detail approach. The process is closely related to the bed shear stress which is influenced by the boundary layer beneath the wave itself (Vittori and Blondeaux 2008). Various studies had been done to investigate the boundary layer beneath a solitary wave. It has been shown that bed stress under a wave runup changes its sign in deceleration phase to the opposite direction of the free stream velocity (Liu et al. 2007). It is also proposed that the deceleration phase has an important role in the turbulent development (Sumer et al. 2010). The direct numerical simulation (DNS) method had been used to investigate the boundary layer under solitary wave (Vittori and Blondeaux 2011). Nevertheless, The DNS method includes more terms and far more complex than the SWE.

Recent development has enhanced the SWE model by coupling with the k- $\omega$ model (Adityawan and Tanaka 2011). Both models were successfully coupled to increase the SWE accuracy by replacing the conventional Manning method with the direct assessment of the bed stress from the boundary layer. The model is applicable to investigate the boundary layer under a wave runup. The method has been verified for the canonical problem and extensively use for various analyses of the bed stress under a non

\footnotetext{
${ }^{1}$ Water Resources Engineering Research Group, Institut Teknologi Bandung, Jalan Ganesha 10, 40132, Indonesia

* Tohoku University, Department of Civil Engineering, 6-6-06 Aoba, Sendai 980-8579, Japan

2 Tohoku University, Department of Civil Engineering, 6-6-06 Aoba, Sendai 980-8579, Japan

${ }^{3}$ State Key Laboratory of Hydraulics and Mountain River Engineering, Sichuan University, Chengdu, Sichuan 610065, China
} 
breaking solitary wave. However, the method was only applied to the non breaking wave case due to the SWE incapability of handling the breaking wave condition.

The boussinesq-type equations (Boussinesq 1872) can be used to simulate the breaking wave condition. The Boussinesq based model with a constant value of eddi viscosity in the shallower area was used to simulate a tsunami wave (Sato and Kabiling 1994). Surprisingly, they have not demonstrated to provide more accurate runup predictions for a tsunami runup even for the landslide wave (Lynett et al. 2003). The volume of fluid (VOF) method which is applied in more advanced numerical models, i.e. NEWFLUME (Lin et al. 1999), gives a more detail process of the breaking wave. However, the model is less flexible to modify for practical application and may be temperamental in term of the model stability.

A finite volume method has the advantage of solving the SWE and maintaining the volume conservation. The shock-capturing numerical method can be used to overcome discontinuities problem. The Godunov-type scheme with the Riemann solver is known for its conserving and shock-capturing capability. A modification of the Godunov-type scheme leads to a second order accuracy in space such as the Monotonic Upstream Scheme of Conservation Laws (MUSCL) scheme (Toro 2001). The method was further enhanced by combining with the First Order Centered Scheme (FORCE) (Toro 1996) and the Total Variation Diminished (TVD) Runge-Kutta. The enhanced method, known as the FORCEMUSCL scheme was employed to solitary wave runup with satisfying results (Mahdavi and Talebbeydokhti 2009). However, the bed stress assessment still relays on the empirical Manning approach.

In this study, the SCM is used to investigate the bed stress under a breaking solitary wave runup on a sloping beach. The SCM employs the boundary layer approach to assess the bed stress that provides higher accuracy than the conventional empirical approach. In addition, the SCM ability is enhanced to cover the breaking wave by applying the FORCE MUSCL scheme.

\section{METHOD}

\section{Simultaneous Coupling Method}

The boundary layer under a solitary breaking wave runup is assessed using the SWE and the k- $\omega$ which are simultaneously coupled. The method simulates the water surface and the depth averaged velocity of a breaking solitary wave runup using the SWE model while the $\mathrm{k}-\omega$ model is used to assess the bed stress. More detail on the coupling method can be found in previous studies (Adityawan and Tanaka 2011, Adityawan et al. 2012).

The coupling method basically upgrades the conventional Manning approach for assessing the bed stress term in the momentum equation of SWE. The depth averaged velocity is assumed equal to the free stream velocity outside the boundary layer. The $k-\omega$ model uses the free stream velocity from the SWE to assess the bed stress in the boundary layer which will be used in the SWE calculation. The $\mathrm{k}-\omega$ model is basically an advancement of the $\mathrm{k}-\varepsilon$ model. The $\mathrm{k}-\varepsilon$ is excellent in reproducing the flow on a large scale such as the flow circulation in a reservoir. Nevertheless, it may not provide satisfying result in a small scale computation such as the boundary layer assessment. Wilcox (1988) has proposed the $\mathrm{k}-\omega$ model, which is considered appropriate particularly for explaining the characteristics of the turbulent flows close to a rough bed. The $\mathrm{k}-\omega$ model provides a better estimation of the boundary layer than the k- $\varepsilon$ model (Suntoyo et al. 2008, Suntoyo and Tanaka 2009). The effect of the roughness account in a simple manner through the boundary conditions at the wall for the specific dissipation rate. Moreover, this model can reproduce the viscous effects close to the wall, appropriately.

The governing equations for the model are the SWE and the k- $\omega$. The SWE equations consist of the continuity equation and the momentum equation as shown bellow.

$$
\begin{gathered}
\frac{\partial h}{\partial t}+\frac{\partial(U h)}{\partial x}=0 \\
\frac{\partial U}{\partial t}+U \frac{\partial U}{\partial x}+g \frac{\partial\left(h+z_{b}\right)}{\partial x}+\frac{\tau_{o}}{\rho h}=0
\end{gathered}
$$


with $h$ is the water depth, $U$ is the depth averaged velocity, $x$ is distance in horizontal plane, $t$ is time, $g$ is the gravity acceleration, $\rho$ is the fluid density and $\tau_{0}$ is bed stress. In the SCM, the bed stress is given by the $\mathrm{k}-\omega$ model from the boundary layer based on the turbulent viscosity $\left(v_{t}\right)$ as given in the bellow.

$$
\begin{gathered}
v_{t}=\frac{k}{\omega} \\
\frac{\tau_{0}}{\rho}=\left(v+v_{t}\right) \frac{d u}{d y}
\end{gathered}
$$

The $\mathrm{k}-\omega$ model governing equation are based on RANS as follows.

$$
\begin{gathered}
\frac{\partial u_{i}}{\partial x_{i}}=0 \\
\frac{\partial u_{i}}{\partial t}+u_{j} \frac{\partial u_{i}}{\partial x_{j}}=-\frac{\partial P}{\partial x_{i}}+\frac{\partial}{\partial x_{j}}\left(2 v S_{i j}-\overline{u_{i}^{\prime} u_{j}^{\prime}}\right) \\
-\frac{\partial P_{i}}{\partial x_{i}}=\frac{\partial U_{i}}{\partial t}+U_{i} \frac{\partial U_{i}}{\partial x_{i}} \\
S_{i j}=\frac{1}{2}\left(\frac{\partial u_{i}}{\partial x_{j}}+\frac{\partial u_{j}}{\partial x_{i}}\right) \\
-\overline{u_{i}^{\prime} u_{j}^{\prime}}=v_{t}\left(\frac{\partial u_{i}}{\partial x_{j}}+\frac{\partial u_{j}}{\partial x_{i}}\right)-\frac{2}{3} k \delta_{i j}
\end{gathered}
$$

where $u_{i}$ and $x_{i}$ denotes the velocity in the boundary layer and location in the grid, $u_{i}{ }^{\prime}$ is the fluctuating velocity in the $x(i=1)$ and $y(i=2)$ directions, $P$ is the static pressure, and $v$ is the kinematics viscosity. The turbulence closure is given as.

$$
\begin{aligned}
& \frac{\partial k_{i}}{\partial t}+U_{j} \frac{\partial k_{i}}{\partial x_{j}}=\tau_{i j} \frac{\partial U_{i}}{\partial x_{j}}-\beta * k \omega+\frac{\partial}{\partial x_{j}}\left[\left(v+\sigma^{*} v_{t}\right) \frac{\partial k}{\partial x_{j}}\right] \\
& \frac{\partial \omega_{i}}{\partial t}+U_{j} \frac{\partial \omega_{i}}{\partial x_{j}}=\alpha \frac{\omega}{k} \tau_{i j} \frac{\partial U_{i}}{\partial x_{j}}-\beta \omega^{2}+\frac{\partial}{\partial x_{j}}\left[\left(v+\sigma v_{t}\right) \frac{\partial \omega}{\partial x_{j}}\right]
\end{aligned}
$$

in which $k$ is the turbulent kinetic energy production and $\omega$ is the dissipation rate. The advantage of $\mathrm{k}-\omega$ model is that it can accommodate the following wall function.

$$
\omega_{w}=U_{o} S_{R} / v
$$

with $U_{o}$ is the friction velocity. In this study, the model is given no slip boundary, thus, $u, v$ and $k$ are zero at bed. Zero gradient is applied giving $d(F) / d y$ equals zero at the free stream. The initial conditions for the parameters were determined by trial and error until it reaches a near constant value.

\section{Breaking Wave Modeling}

The SWE model does not able to simulate the wave breaking condition. The SCM applies a shock capturing scheme, the FORCE MUSCL scheme (Mahdavi and Talebbeydokhtim, 2009), to extend the 
SWE capability for the breaking wave computation. This numerical scheme employs the slope limiter function to handle the shock and discontinuity due to the wave breaking (Toro 2001). The FORCE MUSCL scheme was chosen since it was mainly developed to handle the shock for the wave breaking in the wave runup simulation. Thus, the limiter function would be appropriate for this study. Other methods may employ different types of an artificial dissipation or a limiter function, depending on their use.

The FORCE-MUSCL scheme is based on the finite volume scheme. It is basically a combination of several scheme which combine high dissipation scheme with low dissipation scheme (Lax Friedrich and Lax Wendroff), with the application of slope limiter. The method also uses TVD Runge Kutta to achieve higher stability with non fix times step following the Courrant number criteria of less than 1.

\section{RESULTS AND DISCUSSIONS}

The model was verified with the case of a breaking solitary wave runup on a 1/20 beach (Synolakis 1986). The simulation setup is shown in Figure. 1. The breaking wave condition is given for the ratio of $H / h_{o}$ (the incoming wave height/the initial deep-water depth) of 0.3 with the $h_{o}$ value of 0.13 . The incoming wave Reynolds Number $(R e)$ is 18,000 . This condition still fall in laminar condition based on the criteria by Sumer et al. (2010) in which, $R e$ for transition condition is in the range of $2 \times 10^{5}<\operatorname{Re}<5 \times 10^{5}$. Nevertheless, the $R e$ value may increase significantly in the shallower area. In general, the turbulence production can be observed in the shallower area around the breaking wave region (Sumer et al. 2011, Adityawan et al. 2012).

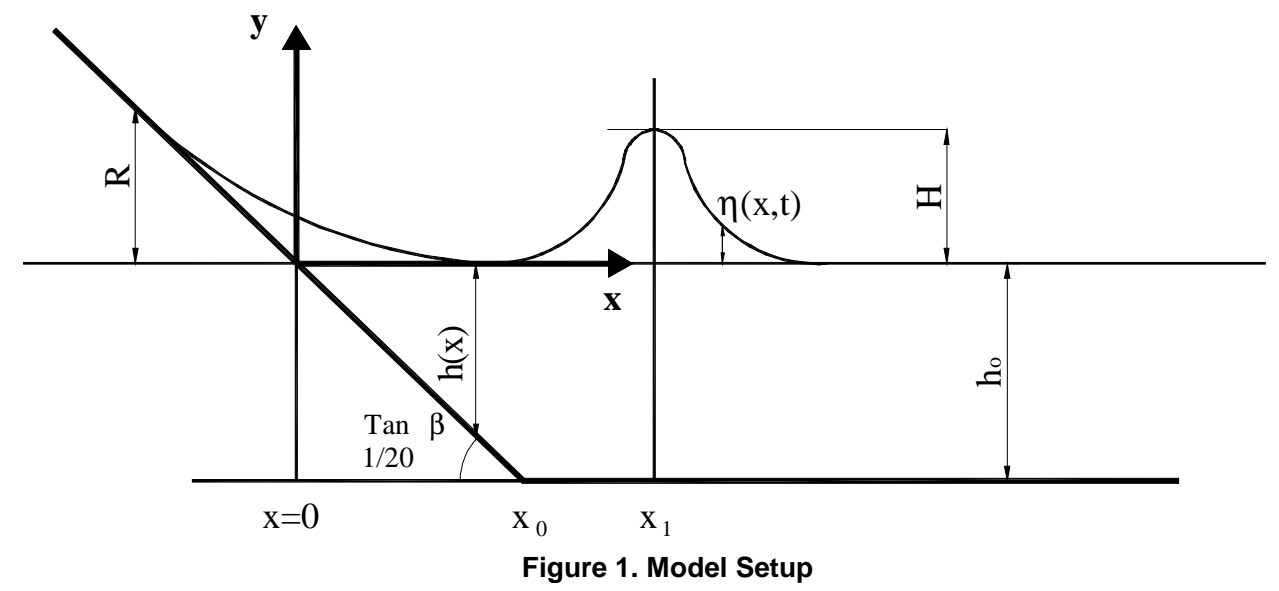

The model was verified with the experimental data and compared with three other numerical models. They are SWE (FORCE MUSCL), SWE (Mac Cormack) and NEWFLUME. In addition, another SCM model with the Mac Cormack scheme was used to evaluate the FORCE MUSCL performance in relation to the SCM. The condition for each simulation was set the same. The horizontal spacing was given by $0.013 \mathrm{~m}$. The vertical spacing was given by 0.0005 meter for the SCM, and 0.001 $\mathrm{m}$ for the NEWFLUME.

Non-dimensional variables are introduced in the analysis as shown in Eq. (13) to Eq. (18) with asterisk $(*)$ corresponds to the non-dimensional form of the variable.

$$
\begin{gathered}
x^{*}=x / h_{o} \\
h^{*}=h / h_{o} \\
t^{*}=t\left(g / h_{o}\right)^{0.5} \\
\eta^{*}=\eta / h_{o} \\
U^{*}=U / U_{c}
\end{gathered}
$$




$$
\tau_{o}^{*}=\tau_{o} /\left(\rho U_{c}^{2}\right)
$$

An example of the wave profile comparison between the experimental data and numerical methods is shown in Figure 2. In addition, the runup height prediction of these models is given in Figure 3. A more detail discussion on the wave profile and the runup height prediction can be found in previous study (Adityawan et al. 2012). Overall, the FORCE MUSCL method gives a more accurate profile than the Mac Cormack method in both the SCM and the conventional SWE. Implementation of the FORCE MUSCL method also provides much better prediction of the runup height for the SWE-type model. On the other hand, the Mac Cormack accuracy seems to decrease with the increase of the wave height. The The NEW FLUME gives the most realistic surface profile. The NEWFLUME is also able to provide information regarding vertical velocity distribution and turbulence near surface, which is very important in the breaking wave process. However, the computation time is about 15 times of the SWE. Overall, for the SWE-type model, the SCM performs better than the conventional SWE. It should be noted that the SCM is able to provide more information on the boundary layer that can not be assessed by the SWE. The direct bed stress assessment from the boundary layer in the SCM leads to an accurate prediction of the runup height as well as the water surface profile.
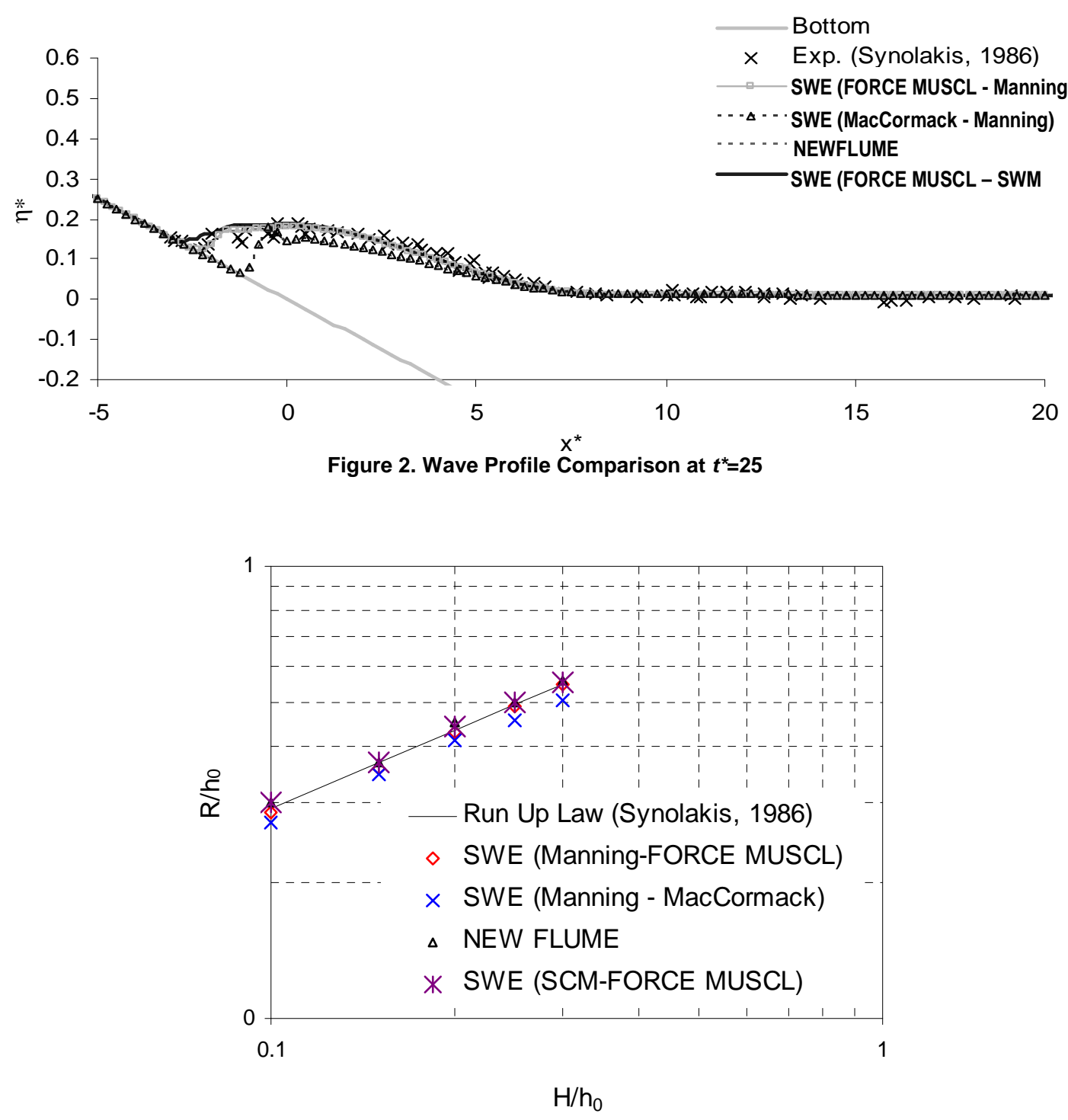

Figure 3. Runup height 
Further evaluation was conducted to understand the breaking wave treatment in the FORCE MUSCL scheme. The method employs the slope limiter function. This function acts as an auto switch, which provides an artificial dissipation to handle the shock and the discontinuity due to the wave breaking (Toro, 2001). It will switch between the mild and the strong dissipation treatment based on the slope limiter function. The dissipation treatments used during the simulation were assigned values corresponds to the treatment and the dissipation rates, ranging from 0 for the lowest (no dissipation), upto the maximum of 2 (strong dissipation). The limiter function affects two parameters. They are the surface elevation $(\eta)$ and the flux $(h u)$.

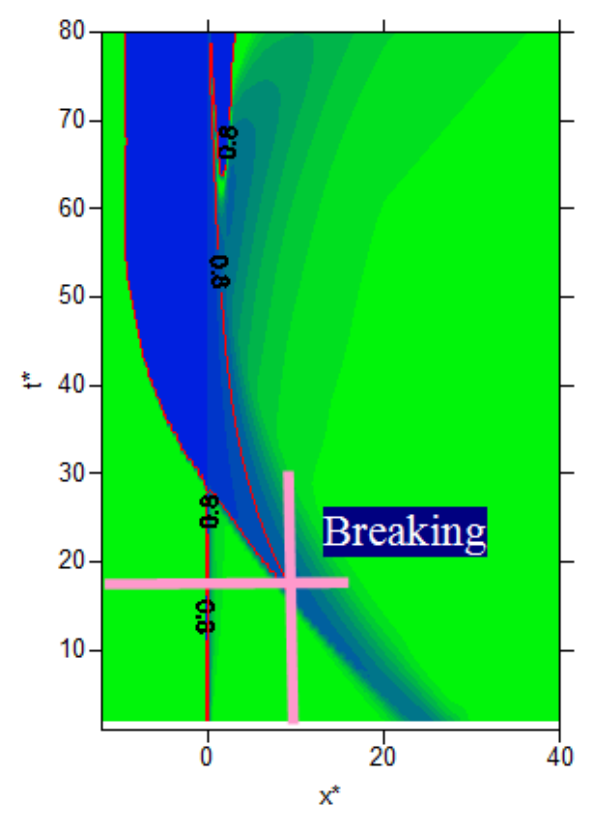

(a) $H / h$

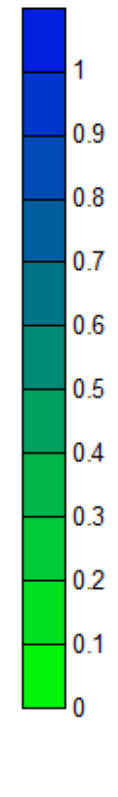

Figure 4. Limiter values for $\eta$

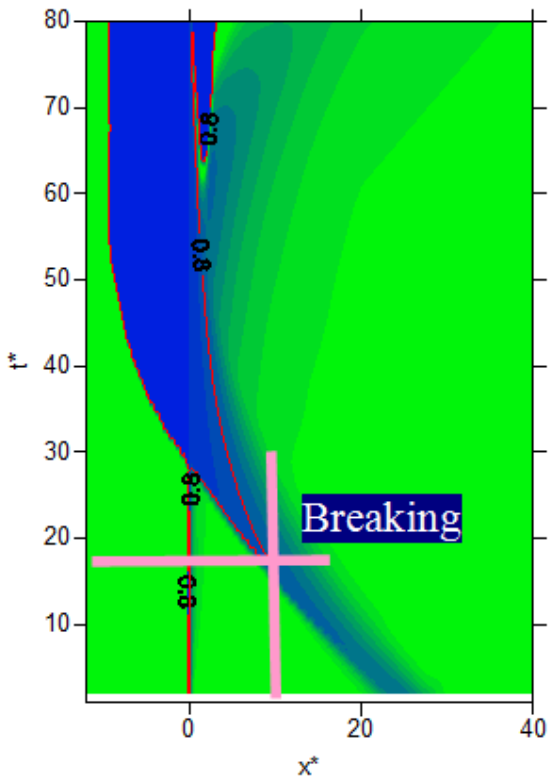

(a) $H / h$

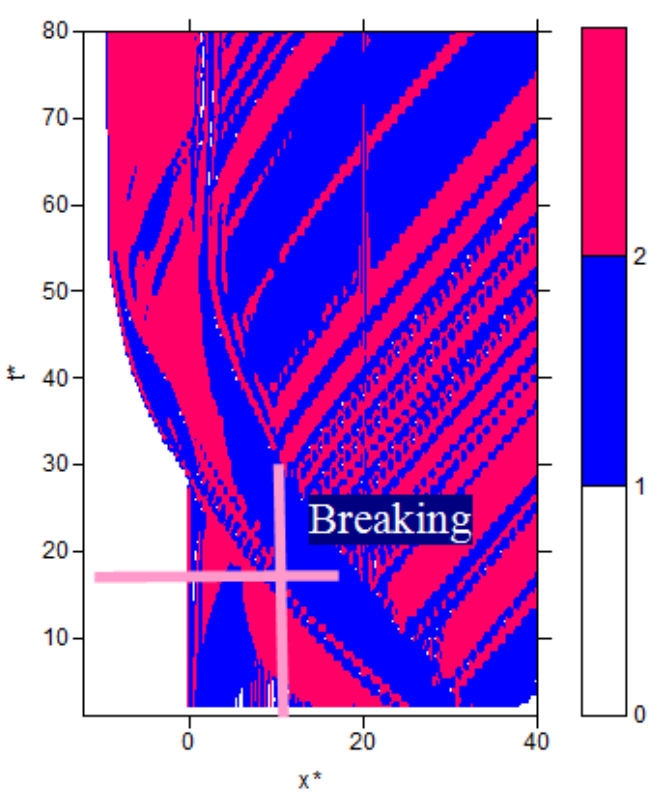

(b) limiter values

\section{Figure 4. Limiter values for $\eta$}


The slope limiter values for the surface elevation and the flux in the space and time is shown in Figure 4 (b) and Figure 5 (b), respectively along with the corresponding free surface condition (Figure 4 (a) and Figure 5 (a)). The slope limiter values between the two parameters are almost identical. Nevertheless, water surface seems to be more sensitive and often switches between the low-strong slope limiter function. Furthermore, during the run down process, the water surface heavily uses the strong dissipation because the water surface parameter is highly affected by the wet/dry treatment and the steep water surface. Identification of breaking wave location is conducted in conjunction with the slope limiter value. There is a sudden change in the slope limiter value from mild to strong dissipation, as shown in Figure 4 (b) and Figure 5 (b). This location is approximately at $x^{*}=10$. Comparison to the wave height ratio over depth shows that the strong dissipation is actively working when the ratio value $(H / h)$ is higher than 0.8 . This value is an acceptable condition and within the range of values where the breaking wave occurs.

The SCM method is able to provide a more accurate prediction of the surface profile as well as the runup height due to the direct estimation of the bed stress from the boundary layer. Figure 6 shows the bed stress comparison from the SCM and the conventional Manning method. The SCM method is able to reproduce known behavior under an unsteady wave motion, i.e. the sign change and the phase shift between the free stream velocity and the bed stress. The Manning method fails to explain these behaviors since it calculates bed stress always in the same direction with the free stream velocity. A closer look to the vertical velocity distribution in the boundary layer clearly show that velocity gradient is not always in phase with the free stream velocity, as shown in Figure 7. This is very important in sediment transport related study.
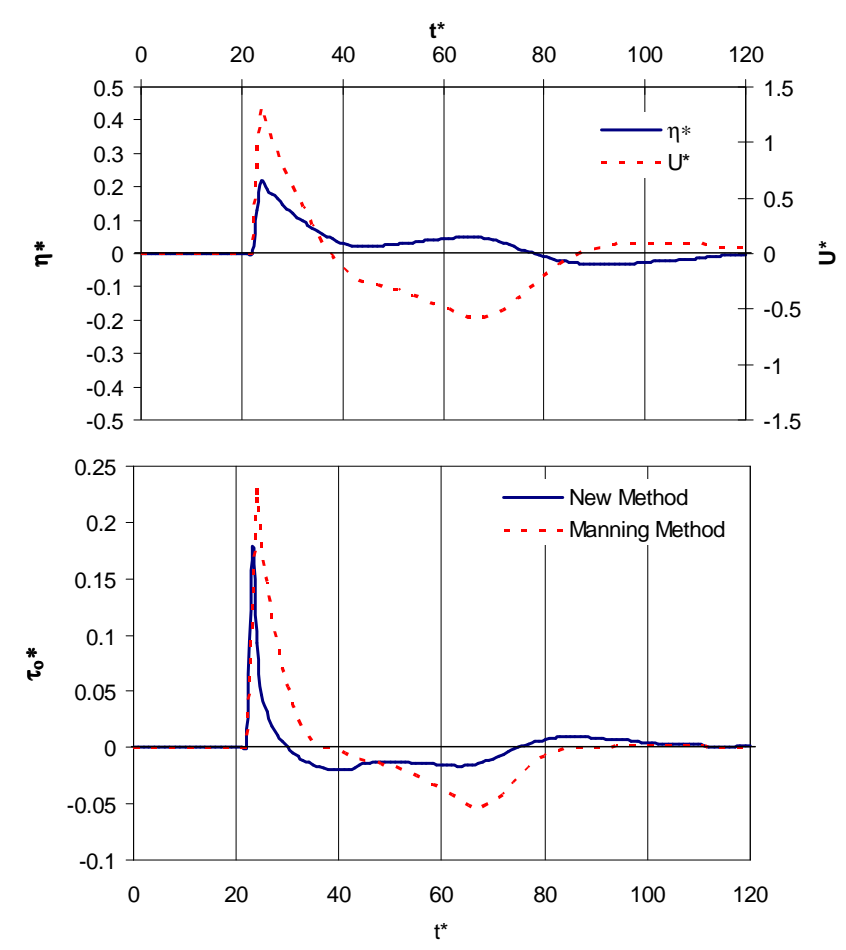

Figure 6. Bed stress comparison at $x^{\star}=2$ 

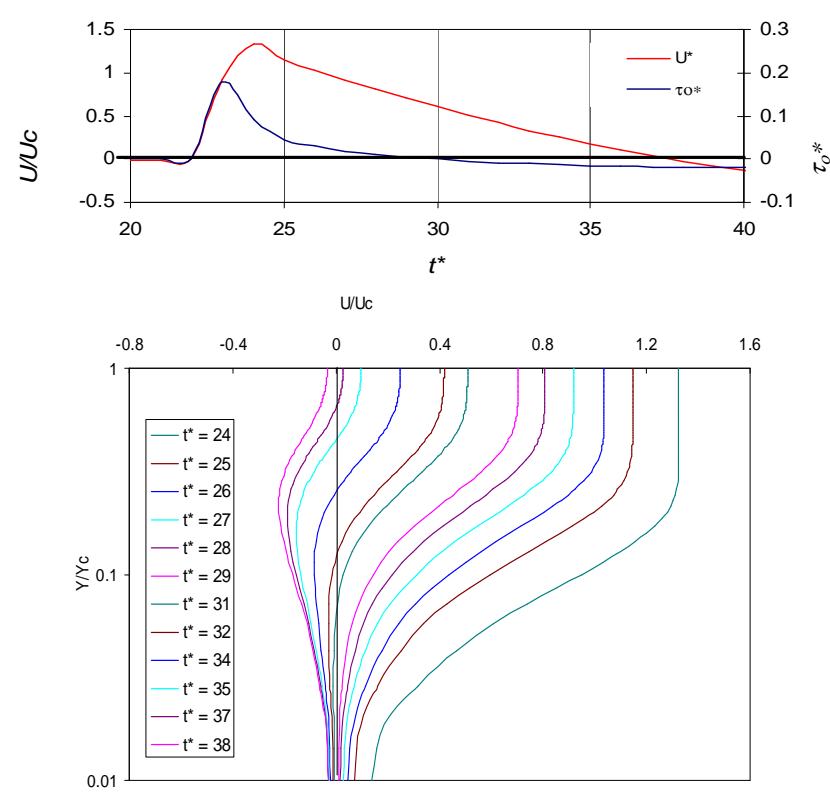

Figure 7. Vertical velocity distribution at $x^{\star}=2$

The bed stress accumulation was further analyzed. The following non-dimensional parameters, which correspond to the statistical features of the bed stress evolution, are introduced.

$$
\begin{gathered}
\overline{\tau_{0}{ }_{(-)}}=\sum_{t^{*}=1}^{T^{*}} \tau_{0} *\left(t^{*}\right)_{(-)} / N_{(-)} \\
\overline{\tau_{0}{ }_{(+)}}=\sum_{t^{*}=1}^{T^{*}} \tau_{0} *\left(t^{*}\right)_{(+)} / N_{(+)} \\
\overline{\tau_{0} *}=\sum_{t^{*}=1}^{T^{*}} \tau_{0} *\left(t^{*}\right) / N
\end{gathered}
$$

where $\overline{\tau_{0}^{*}{ }_{(-)}}$is the average value of negative bed stress, $\overline{\tau_{0}^{*}{ }_{(+)}}$is the average value of positive bed stress, $\overline{\tau_{0} *}$ is the total average bed stress, $\tau_{0} *(t)$ is the recorded bed stress at time $t$ with $\tau_{0} *\left(t^{*}\right)_{(-)}$ and $\tau_{0} *\left(t^{*}\right)_{(+)}$corresponds to negative and positive bed stress value respectively. $N$ is the total number of time with $N_{(+)}$and $N_{(-)}$is the total number of time where the bed stress is positive and negative respectively. Negative and positive sign denotes the direction towards or leaving shoreline respectively. The maximum $\left(\tau_{0} *_{(\max )}\right)$ and minimum $\left(\tau_{0} *_{(\min )}\right)$ value of bed stress is also investigated. In this study, $T^{*}=120$.

The averaged bed stress on the direction toward the shoreline (+) and toward sea (-) were are shown in Figure 8 with (a) and (b) correspond to the estimation from the SCM and the conventional Manning, respectively. It is shown here that the Manning method tends to over estimate the bed stress in the shallower area. The bed stress accumulation provide valuable information to understand bed stress and sediment transport around the shoreline. A balanced budget can be expected in a regular wave motion. However, it is not the case in the solitary wave runup. It is found that bed stress toward the sea has more impact than bed stress on the opposite direction. The extreme values (maximum and minimum) were also recorded and shown in Figure 9. It is shown that bed stress towards the shore is more dominant in the runup zone suggesting that there was a short intense period of extreme bed stress in this area. 
The bed stress accumulation under the non-breaking wave was reported to have significant impact around the shoreline $\left(x^{*}=0\right)$ (Adityawan and Tanaka, 2011). This location is approximately the same for both, the bed stress moving towards the shoreline (+) and leaving the shoreline (-). The bed stress investigation in this study shows different behaviors in the case of the breaking wave runup. The bed stress (-) is observed to have significant impact a bit further to the sea, around $x^{*}=2$, although the location for the bed stress $(+)$ is around the shoreline $\left(x^{*}=0\right)$. The above conditions is caused by the hydraulic jump-like behavior which is often found during the run down process. This phenomenon was found to be stronger in the breaking wave case (Sumer et al. 2011, Adityawan et al. 2012).

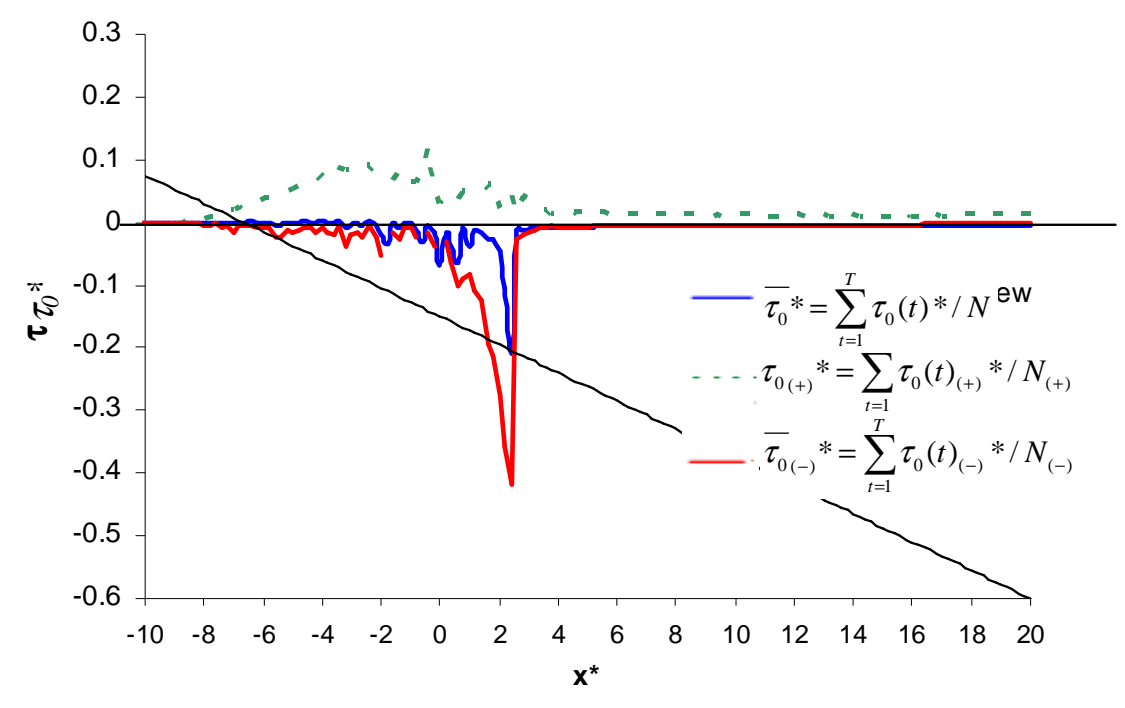

(a) $\mathrm{SCM}$

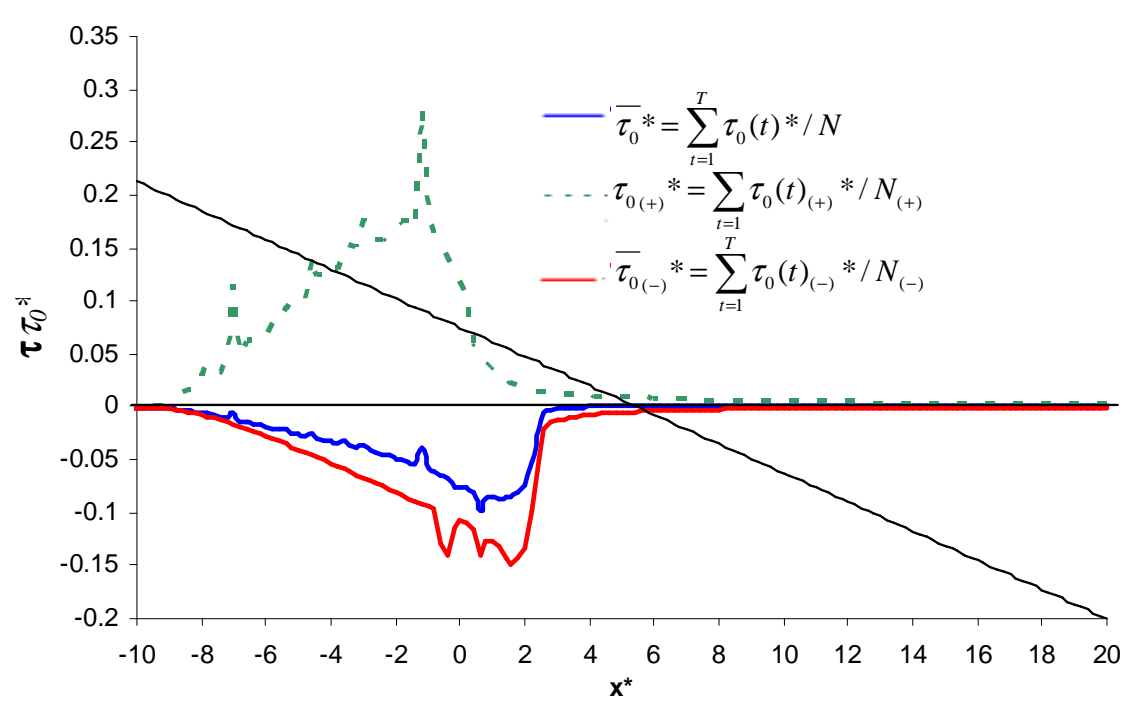

(b) SCM

Figure 8. The bed stress averaged (SCM) 


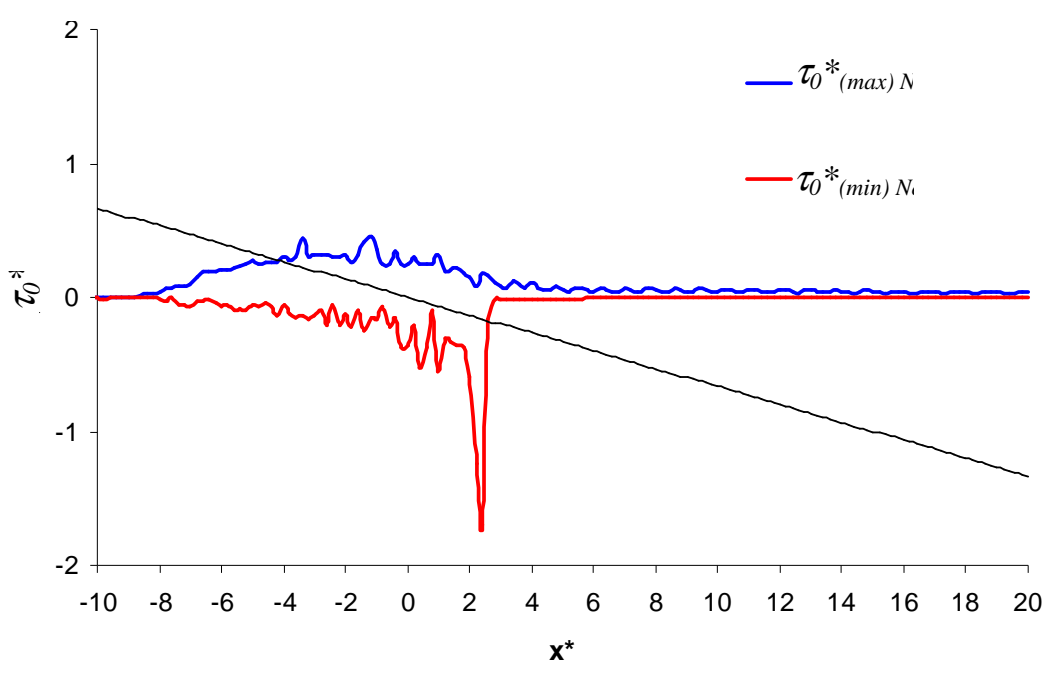

Figure 9. The bed stress extreme values

\section{CONCLUSSIONS}

The SCM has been verified by simulating the case of breaking solitary wave. The SCM assessed bed stress directly from the boundary layer. Thus, the runup height and the surface profile can be accurately predicted. The runup height and the surface profile comparison shows good agreement to the measured values. The adopted breaking wave treatment significantly enhanced the SWE ability for the breaking wave simulation although the results are not as accurate as more advance method such as the VOF. Nevertheless, the FOCE MUSCL scheme is far more efficient when compare to the VOF method. The SWE method with another artificial dissipation method did not perform well when dealing with the breaking wave simulation.

The breaking wave treatment performance was analyzed by analyzing the slope limiter function. The slope limiter function was assigned values that correspond to the dissipation rate at the corresponding location and time. The value ranges from 0 to 2 with 0 is no dissipation and 2 is the strongest dissipation. The slope limiter function is applied to the water level $(\eta)$ parameter and the flux $(h u)$. The values of the slope limiter function were observed in both parameters. It was shown that that it the slope limiter function is more sensitive in the $\eta$ parameter, showing a more frequent changes. Nevertheless, in conjunction with the breaking wave condition, both methods showed similar behaviors. The comparison to the surface water level showed that around the near shore position, there were sudden drop in the water level at the same time and location where there were significant change in the switch, from mild to strong dissipation. This behavior correlates well with the breaking point.

The SCM provides more realistic bed stress estimation than the empirical method (Manning). The comparison of bed stress estimation from both methods (SCM and Manning) shows that the Manning method can not reproduce known behavior of the bed stress under an unsteady wave motion, i.e. the sign change and phase shift between the velocity and the bed stress. The Manning method estimates the bed stress as a function of the velocity vector. Hence, the bed stress from the Manning approach is always in the same direction and phase with the velocity. However, the SCM method provides a more realistic estimation. It clearly explains that the velocity gradient in is not always in the same direction and time with the free stream velocity.

The Bed stress accumulation showed that bed stress with seaward direction has more effect that bed stress with in land direction. Thus, the bed stress on the direction of leaving the shoreline will have more impact in the overall process. However, during a short period of the runup process, the bed stress toward the shoreline may have significant effect as well.

The SCM has shown its capability to assess boundary layer under solitary wave runup. It may provide ways to accurately estimate the bed stress under wave runup, based on the physical process. In addition, the method is efficient and suitable for practical application since it is based on the SWE. Thus, it will be a valuable tool in future study of sediment transport under a breaking solitary wave runup or similar phenomenon, i.e. tsunami. 


\section{ACKNOWLEDGMENTS}

The authors would like to thank the financial supports from Grant-in-Aid for Scientific Research from Japan Society for Promotion of Science (No.21360230, No.22360193, No. 2301367), the River Environmental Fund (REF) from the Foundation of River and Watershed Environmental Management (FOREM), Japan. The first author is a Postdoctoral Fellow granted by JSPS (No. P11367)..

\section{REFERENCES}

Adityawan, M., B., and Tanaka, H. 2011. Bed stress assessment under solitary wave run up, Earth, Planet, Space Journal, Special Issue: Tsunami.

Adityawan, M., B., Tanaka, H., and Lin, P. 2012. Boundary layer approach in the modeling of breaking solitary wave runup, Coastal Engineering Journal, 2012. (in review)

Boussinesq, J. 1872. Thorie des ondes et des remous qui se propagent le long d'un canal rectangulaire horizontal, en communiquant au liquide contenu dans ce canal des vitesses sensiblement pareilles de la surface au fond, Journal de Mathmatique Pures et Appliques, Vol. 17, pp. 55-108.

Kabiling, B. and Sato, S. 1993. Two-dimensional nonlinear dispersive wave-current model and threedimensional beach deformation model, Coastal Engineering, Vol. 36, pp. 195-212.

Kusuma,M., S., B., Adityawan, M.,B., Farid, M. 2008. Modeling two dimension inundation flow generated by tsunami propagation in banda aceh city, Proceedings of International Conference on Earthquake Engineering and Disaster Mitigation, 2008.

Lin, P., Chang, K-A. and Liu, P. L-F. 1999. Runup and rundown of solitary waves on sloping beaches, Journal of Waterway, Port, Coastal, and Ocean Engineering, Vol. 125, No.5, pp. 247-255.

Liu, P. L.-F., Park, Y. S., Cowen, E. A. 2007. Boundary layer flow and bed shear stress under a solitary wave, J. Fluid Mech., Vol. 135, pp. 449-463.

Lynett, P.J., Borrero, J., C., P.L.-F. Liu, and C.E. Synolakis. 2003. Field survey and numerical simulations: a review of the 1998 papua new guinea earthquake and tsunami, Pure and Applied Geophysics, 1Vol. 60, No. 11, pp. 2119-2146.

Mahdavi, A., and Talebbeydokhti, N. 2009. Modeling of non-breaking and breaking solitary wave runup using FORCE-MUSCL scheme, Journal of Hydraulic Research, Vol. 47, No. 4, pp. 476-485.

Nielsen, P. 2002. Shear stress and sediment transport calculations for swash zone modeling, Coastal Engineering, Vol. 45, pp. 53-60.

Sato, S., and Kabiling, B. 1994. A numerical simulation of beach evolution based on a non linear dispersive wave-current model, Proc. 24th Conf. on Coast. Engrg., pp. 2557-2570.

Suntoyo, Tanaka, H., Sana, A. 2008. Characteristic of turbulent boundary layers over a rough bed under saw tooth wave and its application to sediment transport, Coastal Engineering Journal, Vol. 55, pp. 1102-1112.

Suntoyo and Tanaka, H. 2009. Numerical modeling of boundary layer flows for a solitary wave, $J$. Hydro-environment Research, Vol.3, No.3, pp.129-137.

Sumer, B. M., Berke Sen, M. B., Karagali, I., Ceren, B., Fredsøe, J., Sottile, M., Zilioli, L., and Fuhrman, D., R. 2011. Flow and sediment transport induced by a plunging solitary wave, Journal of Geophysical Research, Vol. 116, C010083.

Synolakis, C. E. 1986. The Run-up of Long Waves, PhD Dissertation, California Institute of Technology.

Tanaka, H. and Thu, A. 1994. Full-range equation of friction coefficient and phase difference in a wave-current boundary layer, Coastal Engineering, Vol. 22, pp. 237-254.

Titov, V.V. and Synolakis, C., E. 1998. Numerical modeling of tidal wave runup, Journal of Waterways, Port, Coastal and Ocean Engineering, Vol. 124, No.4, pp. 157-171.

Toro, E.F. 1996. On Glimm-related Schemes for Conservation Laws. Technical Report MMU-9602, Department of Mathematics and Physics, Manchester Metropolitan University UK.

Toro, E.F. 2001. Shock-capturing Methods for Free-Surface Shallow Flows.Wiley, Chichester UK.

Vittori, G., Blondeaux, P. 2008. Turbulent boundary layer under solitary wave, J. Fluid Mech., Vol. 615 , pp. 433-443.

Vittori, G. and Blondeaux, P. 2011. Characteristics of the boundary layer at the bottom of a solitary wave, Coastal Engineering. Vol. 58, pp. 206-213.

Wilcox, D.C. 1998. Reassessment of the scale determining equation for advanced turbulence models, AIAA Journal, Vol. 26, No. 11, pp. 1299-1310. 